\section{COUGHS AND SNEEZES SPREAD DISEASES}

Winter traditionally sees an increase in cases of colds, flu and other unpleasant illnesses, and dental practices can provide the ideal environment for such infections to be transferred. Throughout the working day hands are constantly touching instruments and surfaces, and this can pose a bacterial risk in both clinical and non-clinical areas.

Dentisan offers a range of hand hygiene products specifically designed to prevent this risk, which are all HTM 01-05 compliant. All three products are available in $500 \mathrm{ml}$ bottles or as disposable pouches for use in Dentisan's touchless dispenser. This is the preferred method of dispens- ing hand care products as recommended in HTM 01-05.

Dentiwash is a bactericidal hand and skin cleanser that is perfume and solvent free and contains conditioners for added skin protection.

Dentigel is a post-wash skin disinfectant containing emollients and conditioners and has been microbiologically tested for efficacy against MRSA and E.Coli.

Replenish is a non-greasy emollient cream giving added protection against the possibility of dried and cracked skin.

For more information on the Dentisan hand care range and touchless dispensers visit www. dentisan.co.uk.

\title{
IS YOUR ADMINISTRATOR AN UNSUNG HERO?
}

Go To Job Board (GTJB) has set up a new award to recognise the important work that non-medical and non-clinical NHS staff do. The awards are for the Unsung Heroes of the NHS and look to praise the work of the thousands of support staff that keep the NHS running.

The competition was launched on 1 December 2014 and nominations for your unsung hero can be made at https://www.gotojobboard.com/unsung-hero-awards with the following guidelines:

- Anyone can nominate an individual but that individual must hold a non-medical or non-clinical role

- Nominations are open until 16 January 2015

- The winners will be announced at the beginning of February

- The three winners will receive an iPad Mini and will be featured on GTJB's blog.

Go To Job Board are a specialist job board for non-medical and non-clinical roles. www.gotojobboard.com

\section{MAGICAL TOOL EARNS ACCREDITATION}

The Wand Single Tooth Anaesthesia System has been accredited by the British Dental Health Foundation's independent board of experts.

The Wand is the first computercontrolled local dental anaesthetic machine where just one injection of a single tooth ensures singlesession injection precision.

The benefit of The Wand is a pain-free visit to the dental clinic for

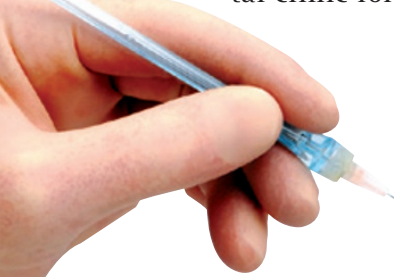

patients, a necessary feature for thousands of patients unwilling to head to the dentist. The Adult Dental Health Survey identified that one in three patients suffer from moderate dental anxiety and roughly one in eight suffer from extreme dental anxiety. However, there are many more who have not come forward.

The Wand's claims to offer pain-free injections can now be substantiated with the Foundation's accreditation. For more information on The Wand visit http://www. painfreedentistry.uk.com/.

\section{CREATE A BESPOKE, RELAXING ENVIRONMENT}

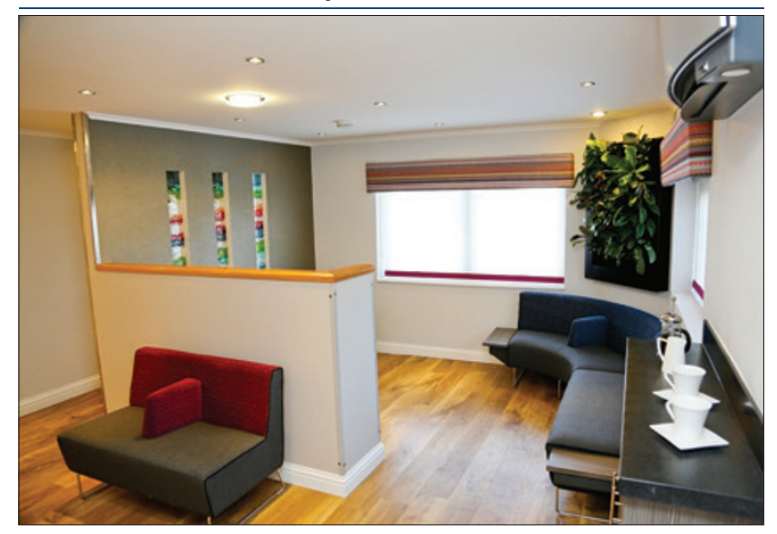

A Berkshire based orthodontic practice has transformed the lives and well-being of both patients and staff after having their premises professionally re-designed by award-winning interior designers, Koubou Interiors.

Koubou Interiors, also Berkshire based, was contacted by husband and wife team Ben and Paula Buffman of Park Lane Orthodontics earlier this year with a brief to create a relaxing and appealing internal environment in which to receive treatment and to work in.

The scope of the design at Park Lane Orthodontics included a Patient Lounge, WC and two consulting rooms. There was also a small amount of work to be done with furnishings but the reception desk was to remain in situ.

The general arrangement plan for the patient lounge included a relaxing and inviting furniture layout, coffee station and other sub areas to include a design in line with the blue and raspberry corporate colours. Koubou were asked to specify and supply wallcoverings and supergraphics which were tactile to the touch with high reflective values and most important of all, to include anti-microbial protection from bacteria in surgery areas that were fully washable and able to withstand the use of chlorinereleasing agents.

In some of the areas, glass was used as a medium to reflect light and colour and showcase the surgery's corporate colours.

Koubou Interiors completed the first stage of the nine month project in just two weeks to keep disruption to the surgery to a minimum and transformed the practice from a bland, uninviting and cold area to a warm, relaxing and inviting space that would welcome patients and improve the working environment of staff.

Koubou Interiors have availability in 2015 to take on more interior design projects for dental and orthodontic surgeries throughout London, the Thames Valley and the South East of England.

Koubou's Managing Director, Gilly Craft, would be very happy to discuss the individual needs and requirements of a practice. Call 01344779323 or visit www.koubouinteriors.co.uk. 